\title{
ANALYSIS OF PHYTO-CONSTITUENTS, ANTIOXIDANT, AND ALPHA AMYLASE INHIBITORY ACTIVITIES OF PERSEA AMERICANA MILL., RHODODENDRON ARBORETUM SM. RUBUS ELLIPTICUS SM. FROM ARGHAKHANCHI DISTRICT NEPAL
}

\author{
BIMALA SUBBA*, SANJAY GAIRE, KHAGA RAJ SHARMA
}

Central Department of Chemistry, Tribhuvan University, Kirtipur, Kathmandu, Nepal. Email: bimalasubba@gmail.com Received: 21 July 2018, Revised and Accepted: 08 October 2018

\section{ABSTRACT}

Objective: To evaluate the phytochemical, antioxidant activities, and $\alpha$-amylase inhibition assay for methanolic extract of three ethnomedicinal plants, namely Persea americana Mill., Rubus ellipticus Sm., and Rhododendron arboretum Sm. collected from Arghakhanchi District of Nepal using in vitro studies.

Methods: Methanolic plant extracts were prepared by cold percolation method. Analysis of phytochemical constituents was carried out using standard methods. The 2,2-diphenyl-1-picrylhydrazyl (DPPH) assay was used to evaluate in vitro antioxidants activities. Furthermore, inhibition effect of extracts on $\alpha$ - amylase enzyme was carried out by using starch as a substrate, pancreatic $\alpha$-amylase as the enzyme, and acarbose as standard.

Results: Phytochemical screening of methanolic extract of all three selected plants displayed the presence of different chemical constituents such as alkaloids, polyphenols, flavonoids, terpenoids, saponins, glycosides, and tannins. The results of DPPH assay revealed that $R$. ellipticus and $R$. arboreum were most active with half maximal inhibitory concentration $\left(\mathrm{IC}_{50}\right)$ values $33.41 \mu \mathrm{g} / \mathrm{ml}$ and $47.28 \mu \mathrm{g} / \mathrm{ml}$, respectively. R. ellipticus was found to be effective toward $\alpha$-amylase inhibition with $\mathrm{IC}_{50}$ values $269.94 \mu \mathrm{g} / \mathrm{ml}$.

Conclusion: The preliminary results of this study have put forward R. ellipticus into promising herbs with good antioxidant activities and $\alpha$-amylase inhibition potential although further studies are needed to assess its mechanism of action.

Keywords: Amylase inhibitor, Antioxidant, Diabetes, Medicinal plants, Phytochemical.

(c) 2019 The Authors. Published by Innovare Academic Sciences Pvt Ltd. This is an open access article under the CC BY license (http://creativecommons. org/licenses/by/4. 0/) DOI: http://dx.doi.org/10.22159/ajpcr.2019.v12i1.29679

\section{INTRODUCTION}

Diabetes is a thoughtful disease increasing at frightening rates around the world. Type II diabetes is a widespread metabolic disorder of fat and carbohydrate metabolism, which is totally connected with food that we ate [1]. Postprandial hyperglycemia (PPHG) is key factors for the development of diabetic complications such as cardiovascular disease, neuropathy, nephropathy, and retinopathy [2,3]. The literature survey revealed that one of the best accepted therapeutic approaches for treating Type II diabetes mellitus is to lower PPHG by preventing the absorption of glucose through the inhibition of the $\alpha$-glucosidase, and $\alpha$-amylase enzymes. These two carbohydrate hydrolyzing enzymes in small intestine break oligosaccharides and disaccharides into monosaccharides, making them available for intestinal absorption to increase blood glucose level immediately after meal [4,5]. Unluckily, the inhibitors of the alpha-amylase enzyme designed as drugs so far, that is, acarbose and sulfonylureas are underwent with several side effects, as well as with financial cost $[6,7]$.

It is well known fact that pancreatic cell damage initiated by reactive oxygen species (ROS) is root foundation of Type II diabetes. ROS also causes damage to cell components such as proteins, lipids, and nucleic acids, which are responsible for causing oxidative stress in many diabetic patients [8]. It is identified that phytochemicals such as polyphenols and flavonoids act as chemopreventive agents against these ROS and also inhibit $\alpha$-glucosidase, and $\alpha$-amylase enzyme, helping to lower down the PPHG with no known side effects so far. These phytochemicals are commonly found in nuts, vegetables, fruits, tea, and medicinal plants [9]. Recently, many papers had been published exposing the chemistry relating the antidiabetic activity of plants [10-12].
Nepal is enrich with variable climate conditions, geographical variation and immense variety of plants with potential antidiabetic activities, but no efforts have been made to seek more safe and efficient antioxidant, $\alpha$-amylase inhibitors from its natural sources so far. Many plants have been commonly used for diabetic treatment all around the world without their scientific evaluations. Therefore, it is urgent to identify and explore the antioxidant amylase inhibitors from natural resources of Nepal. Thus, the present investigation was undertaken to make a comparative study of the ability to inhibit $\alpha$-amylase activity, phytochemical constituents, and assessed their antioxidant properties of the selected plants, that is, Persea americana, Family: Lauraceae., Rhododendron arboreum (Family: Ericaceae), and Rubus ellipticus, belonging to family Rosaceae which are used traditionally for the treatment a number of illnesses including diabetic.

\section{METHODS}

\section{Chemicals and reagent}

The chemicals used in this study were methanol (Merck, Germany), porcine pancreatic $\alpha$-amylase, 2,2-diphenyl-1-picrylhydrazyl (DPPH), and ascorbic acid (Sigma-Aldrich, USA). All additional chemicals used in this research work were of the commercially available analytical grade.

\section{Plant collection and extracts preparation}

Leaves of $P$. americana, $R$. ellipticus, and Rhododendron arboreum were collected from Arghakhanchi District. All collected plants were identified by expert from the Central Department of Botany, Tribhuvan University. Kirtipur, Kathmandu. All collected plant materials were washed with tap water, dried in an oven and powdered. These powders were packed in separate labeled plastic bags and put away from sunlight in cool and dry place until used for the further experiment. The dried powdered were extracted with methanol by cold percolation method. The solvent 
was replaced every $24 \mathrm{~h}$ until extraction was completed. All extracts of each plant were combined and filtered through a porous plug of absorbable cotton. The rotary evaporator was used to concentrate filter at $60{ }^{\circ} \mathrm{C}$ temperature. Finally, the concentrated extracts were fridge dried to yield a dry powder.

\section{Phytochemical screening}

Phytochemical screening is the method of finding the chief group of chemical constituents present in the plant extracts. The phytochemicals were analyzed by following the standard procedures put forward by Ciulei [13]. The diverse phytochemicals in the extracts were identified by the color reaction with different reagents.

\section{Free radical scavenging ability assay}

We followed the adopted methods in our laboratory by Subba et al. 2014 to evaluate the antioxidant activity of test extracts $[14,15]$.

Briefly, $1 \mathrm{ml}$ the each extracts solution comprising appropriate concentration was mixed with $1 \mathrm{ml}, 0.4 \mathrm{mM} \mathrm{DPPH}$ in methanol. The absorbance of the reaction mixture was measured at $516 \mathrm{~nm}$ in a spectrophotometer immediately after incubation for $30 \mathrm{~min}$ in the dark. The DPPH free radical scavenging ability was then calculated using following formula thus:

$$
\% \text { of free radical scavenging activity }=\frac{A_{0}-A_{T}}{A_{0}} \times 100
$$

Where $A_{0}$ is the absorbance without samples extract and $A_{T}$ is the absorbance of samples extract.

\section{Alpha-amylase inhibition assay}

Alpha-amylase inhibition assay was done using a standard protocol with minor variations as explain in brief [16]. The undigested starch due to enzyme inhibition was detected at $630 \mathrm{~nm}$ (blue, starch-iodine complex). The starch solution was ready by dissolving $200 \mathrm{mg}$ starch in $25 \mathrm{ml}$ of $\mathrm{NaOH}(0.4 \mathrm{M})$ through heating at $100^{\circ} \mathrm{C}$ for $5 \mathrm{~min}$, and it was left at room temperature to cool down. The $\mathrm{pH}$ of the cool solution was adjusted to 7.0, and the finally volume was made up $100 \mathrm{ml}$ by adding distilled water. Acarbose was used as a standard inhibitor for alpha-amylase enzyme. $400 \mu \mathrm{l}$ of starch solution was preincubated at $37^{\circ} \mathrm{C}$ for $5 \mathrm{~min}$ with $200 \mu \mathrm{l}$ of acarbose or plant extract at varying concentrations $(40,80,160,320$, 640 , and $1000 \mu \mathrm{g} / \mathrm{ml})$, followed by $200 \mu \mathrm{l}$ of $50 \mu \mathrm{g} / \mathrm{ml} \alpha$-amylase $(20 \mathrm{mM}$ phosphate buffer with $6.7 \mathrm{mM} \mathrm{NaCl}, \mathrm{pH} 6.9)$, and incubated at $37{ }^{\circ} \mathrm{C}$ for $15 \mathrm{~min}$. The reactions were terminated by adding $800 \mu \mathrm{l}$ of $\mathrm{HCl}(0.1 \mathrm{M})$. Then, $1000 \mu \mathrm{l}$ of iodine reagent $(2.5 \mathrm{mM})$ was added, and absorbance was measured at $630 \mathrm{~nm}$. Each assay was carried out in triplicates. Percentage of inhibition was calculated using the formula:

$$
\% \text { Inhibition }=(1-[\text { Abs2-Abs1/Abs4-Abs3] }) \times 100
$$

Where, Abs1 is the absorbance of the reaction mixture containing plant sample, starch, and $\alpha$-amylase, Abs2 is the absorbance of the reaction mixture of sample and starch, Abs3 is the absorbance of the reaction mixture of starch and $\alpha$-amylase, Abs 4 is the absorbance of reaction mixture containing starch only.

\section{RESULTS AND DISCUSSION}

\section{Plant collections}

The tested plants on this research work were selected and collected on the basis of their used traditionally for the treatment a number of illnesses including diabetic (Table 1).

\section{Phytochemical screening}

The result obtained from phytochemical screening for each plant is tabulated as follows in Table 2. Preliminary phytochemical analysis of $P$. americana, $R$. ellipticus, and $R$. arboreum showed positive results for alkaloids, terpenoids, quinones, and flavonoids. These phytochemicals are reported for their various biological activities.

\section{DPPH as an antioxidant}

The methanol extractives of P. americana, R. ellipticus, and R. arboreum were evaluated for free radical scavenging activity. The graph of concentration against the corresponding percentage radical scavenging activity of different samples was plotted (Fig. 1) and concentration providing 50\% inhibition was determined. Ascorbic acid was used as the standard in this experiment.

An half maximal inhibitory concentration $\left(\mathrm{IC}_{50}\right)$ value of $P$. americana, $R$. ellipticus, and Rhododendron arboretum was found $121.39 \pm 0.1333 \mu \mathrm{g} / \mathrm{ml}, 31 \pm 0.2641 \mu \mathrm{g} / \mathrm{ml}$, and $38 \pm 0.15 \mu \mathrm{g} / \mathrm{ml}$, respectively. $\mathrm{IC}_{50}$ value of the standard, that is, ascorbic acid was found to be $22.17 \mu \mathrm{g} / \mathrm{ml}$. Among the test plants, $R$. ellipticus has lower $\mathrm{IC}_{50}$ values followed by other $R$. arboretum, and P. americana, respectively. The high antioxidant activity of the plant $R$. ellipticus is may be due to the phytochemicals such as quinones, flavonoids, terpenoids, and glycosides. These are the major phytochemicals which are known for their antioxidant behavior [17]. Flavonoids isolated from the leaves of $R$. arboreum were reported to have potent antioxidant property [18]. The result is well supported by previously reported the literature.

\section{In vitro $\alpha$-amylase inhibition study}

The mode of $\alpha$-amylase inhibition by the tested plant's leaf extract was determined by the lowest $\mathrm{IC}_{50}$ according to the method given by Bernfeld [16]. Alpha-amylase inhibitory properties are presented in Fig. 2.

In the present study, among the medicinal plants tested, $R$. ellipticus leaves and $R$. arboreum leaves showed moderate inhibition of $\alpha$-amylase activity and weak inhibition activity by P. americana on comparison with standard acarbose Table 3.

The aqueous leaves extracts of $P$. americana possess hypoglycemic activity [19]. Similarly, ether, ethanolic and aqueous extracts from R. ellipticus fruits $(200 \mathrm{mg} / \mathrm{kg})$ are reported for its antidiabetic activity on alloxan-induced diabetes and glucose tolerance test in rats [20]. Bhandary and Kuwabata reported the $\alpha$-glucosidase inhibitory activity of $R$. arboreum and isolated active compounds from it [21]. According to the previous studies, the phytochemicals such as alkaloids, terpenoids, and polyphenols are the major antioxidants. Similarly, the presence of flavonoids and tannins in the extracts is accountable for the antidiabetic activity of the plants [22].

Hence, here the observed $\alpha$-amylase inhibitory activity of test plant extracts might be due to the presence of analogous phytoconstituents which were marked during phytochemical screening, and also due to the witnessed antioxidant potential of the tested plant's extracts. Hence, this study here suggests $R$. ellipticus leaves as good antioxidant as well as good antidiabetic, and $R$. arboreum leaves as a good antioxidant but weak antidiabetic. Both plants have lower $\alpha$-amylase inhibition $\mathrm{IC}_{50}$ value in comparison with acarbose so might be handier in controlling Type II diabetics than acarbose because its strong inhibitory activity toward $\alpha$-amylase is credited for its side effects, that is, due to fermentation of excess undigested carbohydrates in the colon [23].

\section{CONCLUSION}

This study provides some scientific support for their traditional use for diabetes management and other ailments. The author also anticipated that antioxidant properties and inhibition of $\alpha$-amylase by R. ellipticus, $R$. arboretum, and P. americana leaves extract as a probable mechanism for the antidiabetic action. Thus, it can be firm that use of these plant extracts will be greatly subsidized for effective management of Type II diabetes, but further experiments are necessary to find out whether the extract possesses antidiabetic activity under in vivo conditions. Here, it is concluded that further bioassay-guided fractionation approaches will be required on $R$. ellipticus and $R$. arboretum to identify the compounds responsible for their promising in vitro antidiabetic activity. 


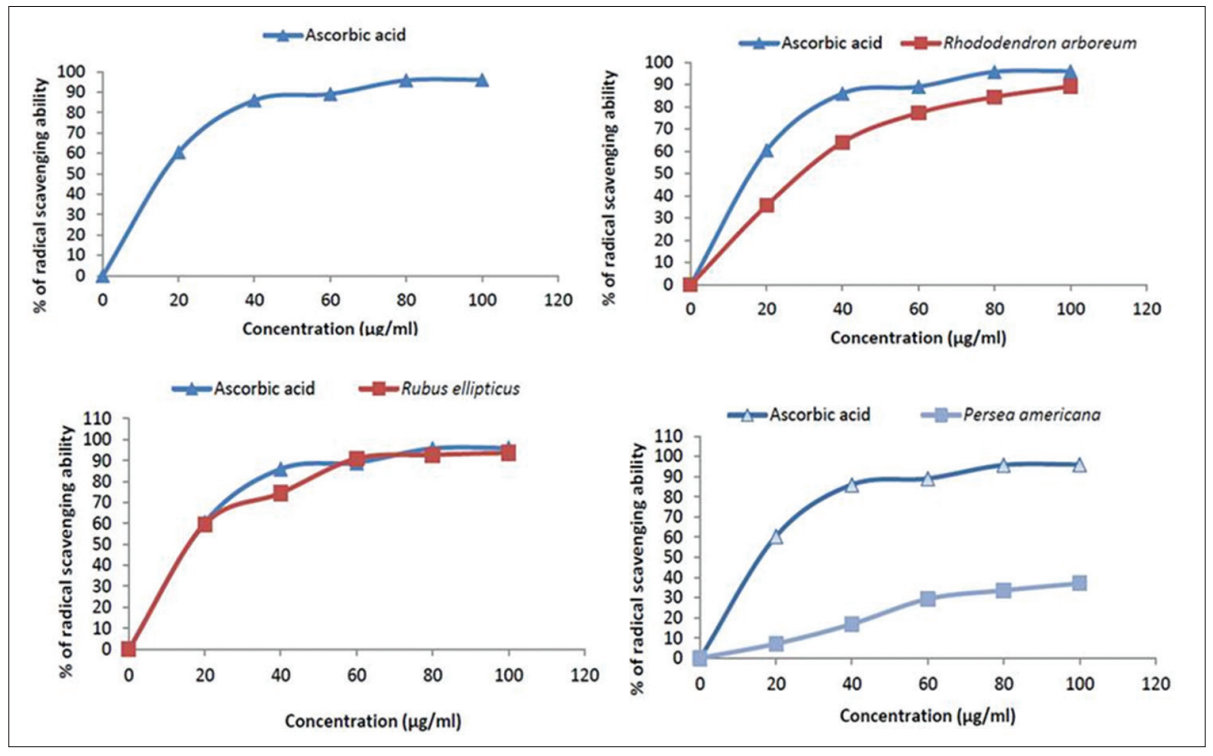

Fig. 1: Results of 2,2-diphenyl-1-picrylhydrazyl scavenging activities of the methanolic extracts of the plants

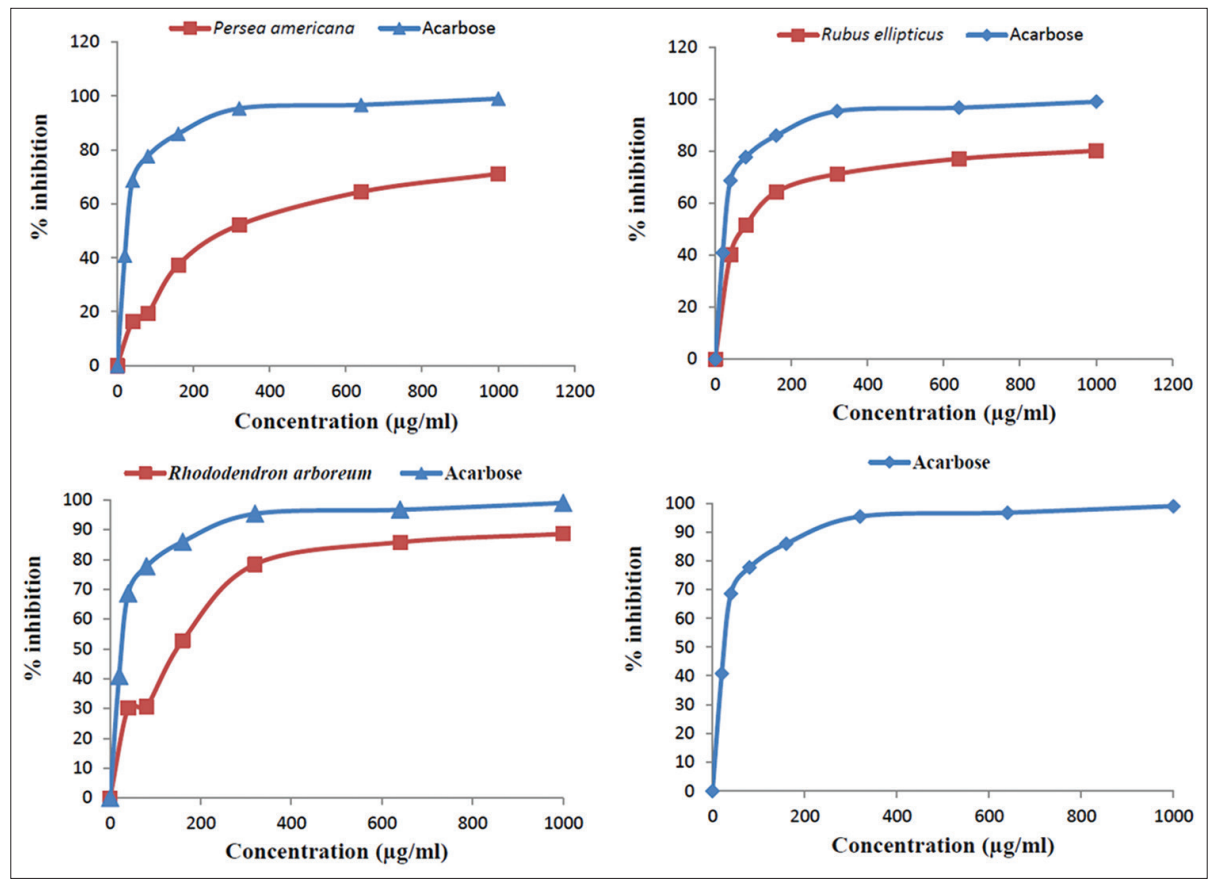

Fig. 2: Inhibition of a-amylase activities by plant extracts

Table 1: Names of the plants, respective family, parts used, and their uses

\begin{tabular}{|c|c|c|c|c|}
\hline Scientific names & Common nepali names & Family & Parts used & Medicinal uses \\
\hline Persea americana & Ghew Phal & Lauraceae & Leaves & Leprosy, fever, asthama, jaundice, and cancer \\
\hline Rubus ellipticus & Ainselu & Rosaceae & Leaves & Bronchitis, ulcers, diarrhea \\
\hline Rhododendron arboreum & Gurans & Apocynaceae & Leaves & Constipation, ringworm infection, and anti-inflammatory \\
\hline
\end{tabular}

Table 2: Results of phytochemical screening of different plant extracts

\begin{tabular}{|c|c|c|c|c|c|c|c|c|c|c|}
\hline \\
\hline \multicolumn{11}{|c|}{ Alkaloids Flavonoids Glycosides Polyphenols Terpenoids Steroids Carbohydrates Saponins Tannins Quinones } \\
\hline Persea americana & + & - & + & + & + & + & - & + & + & + \\
\hline Rubus ellipticus & + & + & + & - & + & - & + & - & - & + \\
\hline $\begin{array}{l}\text { Rhododendron } \\
\text { arboreum }\end{array}$ & + & + & - & - & - & + & - & + & + & - \\
\hline
\end{tabular}

Where, $(+)=$ Present and $(-)=$ Absent 
Table 3: IC ${ }_{50}$ value of extracts on inhibition of $\alpha$-amylase

\begin{tabular}{ll}
\hline Sample name & IC $_{\mathbf{5 0}}(\boldsymbol{\mu g} / \mathbf{m l})($ mean) \\
\hline Acarbose & $144.56 \pm 0.26$ \\
Persea americana & $479.16 \pm 0.10$ \\
Rubus ellipticus & $269.94 \pm 0.11$ \\
Rhododendron arboreum & $298.52 \pm 0.21$ \\
\hline Values are expressed as mean+SD; Values are from triplicate readings. $\mathrm{IC}_{50}:$ Half
\end{tabular}

maximal inhibitory concentration

\section{STATISTICS}

All the analysis was carried out in triplicate, and the results are expressed as mean \pm SD.

\section{ACKNOWLEDGMENTS}

This research work was supported by a faculty research grant from University Grant Commission Nepal (UGC) (faculty research grants 2073-2075). B.S. is a recipient of Faculty research grant, and graciously acknowledges UGC-Nepal for providing Grant. The authors are thankful to the respected Prof. Dr. Megh Raj Pokhrel, former Head of the Central Department of Chemistry, Tribhuvan University, for providing laboratory services to conduct this research work. We would especially like to thank Central Department of Botany, for the identification of collected medicinal plants.

\section{AUTHORS' CONTRIBUTIONS}

B. Subba analyzed the data, and wrote the manuscript, whereas Sanjay Gaire carried out the laboratory work in the guidance of Dr. Khagraj Sharma. All authors read and approved the final manuscript.

\section{CONFLICTS OF INTEREST}

All authors have none to declare.

\section{REFERENCES}

1. Garg A, Bantle JP, Henry RR, Coulston AM, Griver KA, Raatz SK, et al. Effects of varying carbohydrate content of diet in patients with non-insulin dependent diabetes mellitus. JAMA 1994;271:1421-8.

2. Kwon YI, Vattem DA, Shetty K. Evaluation of clonal herbs of Lamiaceae species for management of diabetes and hypertension. Asia Pac J Clin Nutr 2005; 15:107-18

3. Fowler MJ. Microvascular and macrovascular complications of diabetes. Clin Diab 2008;26:77-82.

4. Kim YM, Jeong YK, Wang MH, Lee WY, Rhee HL. Inhibitory effect of pine extraction $\alpha$-glucosidase activity and postprandial hyperglycemia. Nutr J 2005;21:756-61
5. Hanhineva K, Torronen R, Bondia-Pons I, Pekkinen J, Kolehmainen M, Mykkanen $\mathrm{H}$, et al. Impact of dietary polyphenols on carbohydrate metabolism. Int J Mol Sci 2010;11:1365-402.

6. Cheng AY, Fantus IG. Oral antihyperglycemic therapy for Type 2 diabetes mellitus. Can Med Assoc J 2005;172:213-26.

7. Fujisawa T, Ikegami H, Inoue K, Kawabata Y, Ogihara T. Effect of two alpha-glucosidase inhibitors, voglibose and acarbose, on postprandial hyperglycemia correlates with subjective abdominal symptoms. Metabolism 2005;54:387-90.

8. Rahimi R, Nikfar S, Larijani B, Abdollahi M. A review on the role of antioxidants in the management of diabetes and its complications. Biomed Pharmacother 2005;59:365-73.

9. Arranz S, Silvan JM, Saura-Calixto F. Non extractable polyphenols, usually ignored, are the major part of dietary polyphenols: A study on the Spanish diet. Mol Nutr Food Res 2010;54:1646-58.

10. Ali H, Houghton PJ, Soumyanath A. Alpha-amylase inhibitory activity of some Malaysian plants used to treat diabetes; With particular reference to Phyllanthus amarus. J Ethnopharmacol 2006;107:449-55.

11. Akkarachiyasit S, Charoenlertkul P, Yibchok-anun S, Adisakwattana S. Inhibitory activities of cyanidin and its glycosides and synergistic effect with acarbose against intestinal $\alpha$-glucosidase and pancreatic $\alpha$-amylase. Int J Mol Sci 2010;11:3387-96.

12. Tumkur RB, Harishchandra SP. Comparative evaluation of antidiabetic and antioxidant potency of different extracts obtained from Memecylon species. Int J Pharm Pharm Sci 2017:9:187-91.

13. Culie I. Methodology for analysis of vegetable drugs. Practical manuals on industrial utilization of medicinal and aromatic plant, Bucharest. Phytochemistry 1982;63:97-104.

14. Subba B, Basnet P. Antimicrobial and antioxidant activity of some indigenous plants of Nepal. J Pharmacogn Phytochem 2014;3:62-7.

15. Blois MS. Antioxidant determinations by the use of a stable free radical. Nature 1958;26:1199-200.

16. Bernfeld P. Amylases alpha and beta. In: Methods in Enzymology. Vol. 1. New York: Academic Press; 1955. p. 149-58

17. Duraiswamy B, Singanan M, Varadarajan V. Physicochemical, phytochemicals and antioxidant evaluation of Guazuma ulmifolia fruit. Int J Pharm Pharm Sci 2018;10:87-91.

18. Dhan P, Garima U, Singh BN, Ruchi D, Sandeep K, Singh KK. Free radical scavenging activities of Himalayan Rhododendrons. Curr Sci 2007;92:526-32

19. Antia BS, Okokon JE, Okon PA. Hypoglycemic activity of aqueous leaf extract of Persea americana Mill. Indian J Pharmacol 2005;37:325-6.

20. Sharma US, Kumar A. Anti-diabetic effect of Rubus ellipticus fruit extracts in alloxan-induced diabetic rats. J Diabetol 2011;2:1-6.

21. Bhandary MR, Kuwabata J. Antidiabetic activity of Laligurans (Rhododendron arboreum Sm.) flower. J Food Sci Technol Nepal 2008;4:61-3.

22. Sharma VK, Kumar S, Patel HJ, Hugar S. Hypoglycemic activity of Ficus glomerata in alloxan induced diabetic rats. Int J Pharm Sci Rev Res 2010;1:18-22.

23. Kumar S, Narwal SV, Prakash O. $\alpha$-glucosidase inhibitor from plants. A natural approach to treat diabetes. Pharmacogn Rev 2011;5:19-29. 